\title{
Management of COVID-19 Related Myocarditis: A Systematic Review
}

\author{
Şahbender Koç ${ }^{1}$, Yusuf Şener², Emre Doğan ${ }^{3}$, Emine Kırdağ ${ }^{4}$, Emine Altuntaş ${ }^{5}$, \\ Ömer Bedir ${ }^{6}$, Efe Edem ${ }^{7}$ \\ ${ }^{1}$ Medical Doctor, Department of Cardiovascular Surgery, Health Sciences University Ankara Keçiören Education and \\ Research Hospital, ${ }^{2}$ Medical Doctor, Department of Cardiology, Hacettepe University Faculty of Medicine, ${ }^{3}$ Medical \\ Doctor, Department of Cardiovascular Surgery, Health Sciences University Ahi Evran Thoracic and Cardiovascular \\ Surgery Education and Research Hospital, ${ }^{4}$ Medical Doctor, Department of Cardiology, Tokat Erbaa State Hospital, \\ ${ }^{5}$ Medical Doctor, Department of Cardiology, Sancaktepe Şehit Prof. Dr. IIlhan Varank Education and Research Hospital, \\ ${ }^{6}$ Medical Doctor, Department of Cardiology, Dr. Selahattin Cizrelioğlu State Hospital, ${ }^{7}$ Medical Doctor and Associate \\ Professor, Department of Cardiology, Tınaztepe University Faculty of Medicine
}

On January 7 in China, one patient was identified with a new corona virus in throat culture, and World Health Organization called it severe acute respiratory syndrome coronavirus 2 (SARS-CoV-2). Herein, we aimed to summarize overall data for COVID-19 disease related myocarditis and its treatment. In the initial stages, patients developed symptoms of severe acute respiratory infection and afterwards other serious symptoms such as septic shock, metabolic acidosis, coagulation disorders, multiple organ failure problems developed. Complications were mostly associated with pneumonia $(91.1 \%)$ and acute respiratory distress syndrome. Before the Coronavirus Disease 2019 (COVID-19) infection, the presence of cardiovascular diseases has been found to increase the severity and side effects of primary respiratory syndrome. Since management of COVID-19 related myocarditis is crucial, 114 publications indexed in Pubmed between Dec 10, 2019 and October 16, 2020 were scanned extensively in this review in order to summarize the treatment options of COVID-19 related myocarditis. Analysis of 44.672 COVID-19 cases showed an increased risk of mortality in elderly people ( $14.8 \%$ for patients over 80 years old) and patients with cardiovascular disease $(10.5 \%)$. Patients with diabetes $(7.3 \%)$ and hypertension $(6 \%)$ also demonstrated an increased risk of mortality. The rate of underlying chronic respiratory disease was $6.3 \%$. Arrhythmia was found in $16.7 \%$ and acute heart injury existed in $7.2 \%$ of 138 hospitalized COVID-19 patients. ACE inhibitors or ARBs should be administered in patients with wall motion abnormality or heart failure with reduced EF. Diuretics should be considered in patients with volume overload and torsemide should be preferred as first option. Non-steroidal antiinflammatory drugs and cardiac glycosides should be avoided. Physical activity should be restricted until the disease resolved. IVIG and interferon therapy are feasible treatment options with reasonable side effect profile.

Key words: COVID-19; Myocarditis; Arrhythmia; Diuretics; Systematic Review

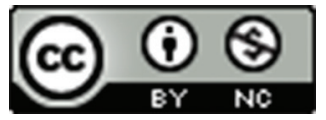

This work is licensed under a Creative Commons Attribution-NonCommercial 4.0 International License.

\section{INTRODUCTION}

On January 7 in China, one patient was identified with a new corona virus in throat culture, and World Health Organization (WHO) called it severe Acute Respiratory Syndrome Coronavirus 2 (SARS-CoV-2). In the initial stages, patients developed symptoms of severe acute respiratory infection and afterwards other serious symptoms such as septic shock, metabolic acidosis, coagulation disorders, multiple organ failure problems developed. ${ }^{1,2}$ Complications were mostly associated with pneumonia (91.1\%) and acute respiratory distress syndrome. ${ }^{3,4}$ In the 2020 report prepared by the China Medical Treatment Group for Coronovirus Disease 2019 (COVID-19), it was reported that during hospitalization, fever up to $88.7 \%$, cough in $67.8 \%$, then dry cough, headache, fatigue or shortness of breath. ${ }^{5}$ 
Before the COVID-19 infection, the presence of cardiovascular diseases has been found to increase the severity and side effects of primary respiratory syndrome. ${ }^{6}$ Analysis of 44.672 COVID-19 cases showed an increased risk of mortality in elderly patients (14.8\% for patients over 80 years old) and diabetes $(7.3 \%)$, hypertension $(6 \%)$ and cardiovascular patients $(10.5 \%)$. The rate of underlying chronic respiratory disease was $6.3 \%{ }^{7}$ Arrhythmia was found in $16.7 \%$ and acute heart injury in $7.2 \%$ of 138 hospitalized COVID-19 patients. ${ }^{8}$ In one study, 23.0\% of patients with COVID-19 infection had heart failure. Heart failure was higher in patients who lost their lives than the survivors $(51.7 \%$ vs. $11.7 \%$ ). The reason for this is unknown whether heart failure deaths occurred due to new cardiomyopathy (myocarditis or stress cardiomyopathy) or pre-existing left ventricular dysfunction. ${ }^{9}$

Troponin is the most specific laboratory finding of injury due to myocarditis, acute coronary syndrome, or myocardial injury. In one study, $20 \%$ of died patients had cardiac injury characterized by high sensitive troponin (Hs-troponin) levels. In the multivariable adjusted model, cardiac injury was significantly and independently linked to mortality (hazard ratio: 7.89$) \cdot{ }^{10}$ In the another study, in multivariate logistic regression analysis, high cTnI $(\mathrm{OR}=26.909,95 \% \mathrm{CI} 4.086-177.226, \mathrm{P}=0.001)$ and coronary artery disease $(\mathrm{OR}=16.609,95 \%$ CI 2.288 $120.577, \mathrm{P}=0.005$ ) was found as independent risk factors for critical disease. ${ }^{11}$

In a study involving 187 patients with COVID-19, troponin levels and mortality rates were higher in patients using angiotensin converting enzyme inhibitor (ACEI) / Angiotensin receptor blocker (ARB) than those who did not ([21.1\%] vs [5.9\%], [36.8\%] and [25.6\%]). In patients with high plasma TnT levels, who were eventually discharged or died, mean duration time of the disease from onset to discharge or death (IQR) was 28 (22-33) and 23.5 (18.25-34.5) days, respectively. Patients with hypertension $(63.5 \%$ vs $20.7 \%)$, coronary heart disease $(32.7 \%$ vs $3.0 \%)$, cardiomyopathy ( $15.4 \%$ vs 0$)$ and diabetes $(30.8 \%$ vs $8.9 \%)$ had higher TnT levels. ${ }^{12}$

The obvious relationship between TnT levels and C-reactive protein and $\mathrm{N}$-terminal pro-B-type natriuretic peptide (NT-proBNP) levels indicates that myocardial injury is associated with the severity of inflammation and ventricular dysfunction. Acute respiratory distress syndrome (ARDS), malignant arrhythmias, acute renal injury, and acute coagulopathy were more common in those with high TnT levels. It was found that the increase of these three parameters was related to the poor prognosis and the decrease was related to the good prognosis. In patients with cardiovascular disease and troponin increase, death rate was $69 \%$, in those without cardiovascular disease and troponin increase, death rate was $37 \%$, and in those with cardiovascular disease and normal troponin level, the mortality rate was $13 \%$. Acute myocarditis, in addition to acute coagulopathy, could explain cases of sudden cardiac death observed during quarantine among COVID-19 patients not admitted to hospital. ${ }^{12}$

\section{CORONAVIRUSES}

Coronaviruses (CoVs) are single-stranded positive-sense RNA viruses, comprises of a large family of viruses that are common in human beings as well animals (camels, cattle, cats, and bats). CoVs are named for crown like spikes on their surface and belong to the Coronavirinae subfamily, which are further classified into four genera: the $\alpha, \beta, \gamma$, and $\delta \mathrm{CoVs}$ by phylogenetic clustering, of which $\alpha$ and $\beta$ are known to cause infection in humans. ${ }^{13}$

At the end of 2019, the first pneumonia cases of unknown origin were identified in Wuhan, a city in the Hubei Province of China. ${ }^{14}$ The pathogen has been identified as a novel enveloped RNA betacoronavirus that has currently been named as SARS-CoV-2, which has a phylogenetic similarity to SARS-CoV. ${ }^{15}$ It rapidly spread, resulting in an epidemic throughout China and then gradually spreading to other parts of the world in pandemic proportions. In February 2020, the World Health Organization designated the disease COVID-19, which stands for corona virus disease $2019 .{ }^{16}$

Transmission of SARS CoV-2 seems to be primarily from person to person via close contact and through respiratory droplets. The exact incubation period is not known. ${ }^{17,18} \mathrm{It}$ is presumed to be between 2 to 14 days after exposure, with most cases occurring within 5 days after exposure. ${ }^{19}$ These values should help inform COVID-19 case definitions and appropriate quarantine durations.

People with COVID-19 have had a wide range of symptoms reported-ranging from mild symptoms to severe illness. The three primary symptoms of COVID-19 are fever, cough, and shortness of breath or difficulty breathing. Less common symptoms are muscle pain, anorexia, new loss of taste or smell, sore throat, nasal congestion, and headache. These symptoms may appear in as few as 2 days or as long as 14 days after exposure. ${ }^{20}$ Also, gastrointestinal symptoms, such as diarrhoea, abdominal pain, and vomiting, have been reported in $2 \%$ to $10 \%$ of patients with COVID- $19 .{ }^{21}$

Diagnosis is currently through SARS-CoV-2 real-time reverse transcriptase polymerase chain reaction diagnostic panel using upper and lower respiratory specimens. ${ }^{22} \mathrm{New}$ 
serologic tests, at-home test kits, and point-of-care tests are likely to become available in the near future.

COVID-19 mainly affects the respiratory tract and can progress in severe cases to pneumonia, acute respiratory distress syndrome and multi-organ failure. With the increasing number of infected cases, COVID-19 has been shown to cause cardiovascular injury, in addition to typical respiratory symptoms. This condition can, in fact, cause significant myocardial injury, which worsens the disease and affects the prognosis.

\section{PATHOGENESIS AND DIAGNOSIS}

The virus binds to the ACE2 receptor with the Spike (S) glycoprotein of SARS-CoV-2 and enters the cell. SARSCoV-2 primarily occupies the alveolar epithelial cells and creates respiratory symptoms. ${ }^{23}$ The ACE2 receptor is retained by some coronaviruses, its primary physiological role is the maturation of angiotensin, a peptide hormone that controls vasoconstriction and blood pressure. ACE2 is a type I membrane protein that is expressed in the lungs, heart, kidneys, and intestine. Decreased ACE2 expression is associated with cardiovascular diseases. ${ }^{24}$

Viral myocarditis and injury mechanisms are uncertain. Possible mechanisms are discussed.

1. Increased heart load: In viral infections, the load of the heart increases about 4-8 times as much as in important exercises. It can decrease cardiac functions in pneumonia, infection-induced increase in metabolic demand and reduced cardiac reserve.

2. Increased expression of Angiotensin Converting enzyme 2 (ACE2): Because ACE2 is involved in lung protection, binding of the virus to this receptor contributes to viral pathogenicity. ${ }^{25}$ ACE2 expression is increased in the lung, although it is not certain, it has been accused of higher levels of ACE2 in myocardial injury. The severity of the disease in those with cardiovascular diseases, relative to healthy individuals, may be associated with increased ACE2 secretion in these patients. ${ }^{26}$ It has been stated that there is an increase in ACE2 expression especially in pericytes in myocardium of heart failure patients and therefore, these patients may be more sensitive to SARS-CoV-2 infection. ${ }^{27}$

3. Excessive inflammation: Excessive inflammatory cell infiltration was detected in the alveoli of patients who developed acute respiratory distress syndrome due to SARS-CoV-2 infection. ${ }^{28}$ Excessive inflammatory activity by SARS-CoV-2 can be suppressed with corticosteroids. Therefore, it has been stated that exaggerated inflammation may be responsible for viral injury, this explains the extensive corticosteroid use in critical COVID-19 patients. ${ }^{29}$ The patients who died had higher levels of troponin, myoglobin, C-reactive protein, serum ferritin, and interleukin- 6 , so it was thought that myocarditis-related cardiac events were likely to occur due to the high inflammatory load. ${ }^{30}$ Stimulating excessive cytokine release by type 1 and 2 Thelper cells. HsCRP and cytokine levels were found to be associated with cardiovascular risk.

4. Hypoxemia: Hypoxemia and respiratory dysfunction harm myocardial cells. Respiratory acidosis increases loading of the right ventricle which results in tachycardia, increased wall stress, and extend of tissue damage.

5. Coronary plaque destabilization and procoagulation: Destabilization of coronary artery plaques occur due to inflammation. In patients with coronary artery disease and heart failure, there is a risk of coronary plaque rupture secondary to the virus-induced systemic inflammation. Vascular inflammation creates endothelial dysfunction and an increased state of coagulation. ${ }^{31,32}$ Pro-coagulating effects of systemic inflammation may also increase the risk of stent thrombosis. ${ }^{33}$ The tendency to type 2 myocardial infarction increases due to infection induced myocardial demand. ${ }^{34}$

6. Direct effect on myocard: In a study conducted in $2009,35 \%$ of patients with severe acute respiratory syndrome due to SARS-CoV infection had a virus genome in the heart, suggesting the possibility of direct damage to the virus. ${ }^{35}$ SARS-CoV-2 may have the same mechanism as SARS-COV because it is highly homologous in 2 virus genomes. ${ }^{36,37}$ COVID - 19 RNA has been detected in the small and large intestine, lymph nodes, spleen, liver, heart, kidney, skeletal muscle, adrenal gland and cerebrum as a result of extrapulmonary spread. ${ }^{38}$ The pathogenesis of SARS-CoV-2-related cardiac involvement can be related to the proliferation and spread of the virus from the blood or respiratory system lymphatic system. There is ACE2 receptors in the vascular endothelium and myocard, the possibility of virus damage to the endothelium and myocardium. ${ }^{39}$

7. Immune function weakness: There are common mechanisms that lead to CVD and regulation of immune function. Age is the strongest risk factor for CVD, and is important for susceptibility and severity to COVID-19. ${ }^{40}$

Although the symptoms are mostly respiratory, cardiac involvement may occur as a late finding. Cardiac involvement, as shown in the autopsy study, may be subclinical with several inflammatory cells, or significant 
cardiac manifestations may be detected without respiratory symptoms. Many viral infections, such as influenza and parvovirus B-19, which have myocardial involvement, have been identified. ${ }^{41}$

Necrosis and eventually ventricular dysfunction occurs in myocarditis caused by focal or global myocardial inflammation. Patients develop chest pain after an influenza-like syndrome. There may be signs of acute coronary syndrome in electrocardiography or laboratory tests. However, obstructive coronary artery disease is not detected in coronary angiography. Focal myocarditis is often suspected with wall motion disorders and clinical evidence. ${ }^{42}$

The cardiac findings first described in COVID-19 infection were palpitations and chest pain. ${ }^{43}$ Other published and anecdotal reports include myocarditis, cardiac arrest and acute heart failure. There may be symptoms of chest pain, dyspnea, palpitations, fever, tachycardia and depending on severity hypotension and low oxygen saturation, heart failure symtomps and shock. In patients with atypical chest pain and minimal respiratory distress, increased troponin levels may be a stimulant for acute myocarditis. ${ }^{44,45}$

Since magnetic resonance and endomyocardial biopsy are not always used in COVID-19 patients, the frequency of acute myocarditis was reported as $12.5 \%$ in a patient series based on elevation of troponin level, electrocardiogram (ECG) (ST/T segment changes), transthoracic echocardiography (TTE) (wall motion abnormalities, left ventricular ejection fraction $(\mathrm{LVEF})<50, \mathrm{LV}$ wall thickening $>10 \mathrm{~mm}$ and/or pericardial effusion) findings. The most common echo finding was pericardial effusion and the frequency of arrhythmia was $16 \%{ }^{46}$

There is limited information about cardiac involvement due to SARS-CoV-2 infection. The examinations suggested in the scarce literature for COVID-19 myocardial injury or myocarditis is listed below.

Swabs: Nasopharyngeal and oropharyngeal swabs (for reverse transcriptase polymerase chain reaction assay)

Lab: Greater leukocyte counts, lenfopenia, high-sensitivity troponin T,NT-proBNP, C-reactive protein, creatine kinase, myoglobin, procalcitonin, $\mathrm{D}$-dimer, ferritin

Chest X-ray: Opacities,infiltration,etc.

ECG: ST depression, elevation, arrhythmia, tachycardia, QTc meauserement (>500ms), etc.

Chest Computed tomography (CT): Especially groundglass opacity; in early chest computed tomography, it was reported that $85 \%$ of patients had findings, and $75 \%$ of patients had ground-glass opacity and consolidation in the subpleural and peripheral areas. ${ }^{47} \mathrm{CT}$ also rules out acute life-threatening clinical settings such as aortic dissection, pneumothorax and pulmonary embolism.

TTE: hypokynesis, dilatation, effusion, etc.

Coronary CT angiography: It is recommended to rule out coronary artery disease (CAD),

Cardiac magnetic resonance (CMR): Myocardial edema, pseud-hypertrophy, late gadolinium enhancement sequences for detectable myocardial scar/necrotic foci, etc.

Endomyocardial biopsy (EMB): T-lymphocytic inflammatory infiltrates, interstitial edema, foci of necrosis, fibrosis, viral particle detection.

Molecular analysis: Used for SARS-CoV-2 genome within the myocardium.

The number of case reports on myocarditis is increasing. One patient had SARS-CoV-2 positivity in nasopharyngeal and oropharyngeal swabs. Diffuse T-lymphocytic infiltration (CD3 +> $7 / \mathrm{mm} 2$ ), diffuse interstitial oedema and limited necrosis areas were detected in endomyocardial biopsy. SARS-CoV-2 genome was not able to be detected in the myocardium in the molecular analysis. Thus, acute virusnegative lymphocytic myocarditis has been diagnosed..$^{48}$

EMB was performed in a SARS-CoV-2 patient who recovered after development of sudden cardiogenic shock. Low-grade interstitial and endocardial inflammation, large $(>20 \mu \mathrm{m})$ vacuole, CD68 - positive macrophages, membrane damage and cytoplasmic vacuoles were detected in pathologic examination. Typical viral particles of 70$120 \mathrm{~nm}$ in size were detected in cytopathic interstitial inflammatory cells. No viral particles were detected in myocytes. This is thought to be the result of either the extra-pulmonary spread of infected alveolar macrophages or viremic phase. ${ }^{49}$

As our experience of this epidemic increases, which we are still trying to understand, questions regarding myocardial injury can be fully answered. Myocarditis is identified as inflammation of heart muscle cells. The causes of inflammation can be external antigens such as viruses, bacteria, parasites, toxins and drugs or internal triggers such as autoimmune activation against self antigens. The diagnosis of myocarditis is diffucult, as it requires endomyocardial biopsy. Therefore it is hard to truly detect the incidence of cardiac involvement. The Dallas criteria are used for histopatologic diagnosis: 
- Myocarditis: Presence of inflammatory cells and myocyte necrosis findings on the same microscopic section.

- Borderline myocarditis: Presence of inflammatory cells infiltrates without of necrosis.

- No myocarditis: There are no inflammatory cells and necrosis. ${ }^{50-51}$

\section{CLINICAL PRESENTATIONS AND PHYSICAL EXAMINATION FINDINGS}

Clinical presentation of myocarditis may be asymptomatic or may be with chest pain. The chest pain mostly relates with acute pericarditis and rarely associates with coronary artery vasospasm. In patients with myocarditis, arthralgias, malaise, fever, sweats, chills can occur at the same time with myocarditis or before the myocarditis. When heart failure occurs, the main symptoms are dyspnea, fatigue, edema. In some patients who have heart failure, fatigue and decresead functional capacity are initial symptoms. In some cases, arrhytmias can be seen which cause syncope, tachyarrhytmia or sudden cardiac death. These symptoms are similar in patients with COVID-19 myocarditis.

Acute decompensated heart failure signs mostly include an S3 gallop, central and peripheral edema, juguler venous distention, tachycardia. If acute pericarditis accompanies, pericardial friction rub may be audible..$^{50,52-54}$

\section{LABORATORY EVALUATION}

In these patients, $C$ reactive protein(CRP), erytrocyte sedimentation rate(ESR),procalcitonin white blood count levels are high. When myocardial injury accompanies, troponin $\mathrm{T}(\operatorname{Tn} \mathrm{T})$ or $\mathrm{I}$, creatin kinase $(\mathrm{CK}) \mathrm{CK}-\mathrm{MB}$, myoglobin $\mathrm{N}$ terminal pro $\mathrm{B}$ type natriuretic peptide(NTproBNP) level increase. Guo et al. found in their study that $\operatorname{Tn} T$ levels are significantly associatedwithlevels of C-reactive protein and N-terminal pro-B-type natriuretic peptide (NT-proBNP), thus linking myocardial injury to severity of inflammation and ventricular dysfunction. ${ }^{55}$

In ECG of these patients, there are nonspesific ST-T changes, $\mathrm{T}$ wave abnormalities, sinus tachycardia. Occasionally, ST elevation is seen in ECG, when pericarditis accompany myocarditis. I to III degree atrioventricular block, left bundle brunch block, sinus arrest, ventricular fibrillation or tachycardia, asystole, atrial fibrillation, reduced $\mathrm{R}$ wave height, abnormal $\mathrm{Q}$ wave, low voltage, premature beats can also be seen.

TTE is another diagnostic tool. In echocardiography, regional or global wall motion abnormalities, ventricular dilatation, pericardial effusion, intracardiac thrombus can be established. Also, coronary angiography can be done to exclude coronary artery abnormalities.

Lastly, CMR can be chosen to diagnose myocarditis. In CMR, edema can be established. Late gadolinium enhancement which is classical myocarditis pattern can be identified. ${ }^{53,54}$

\section{TREATMENT OF SARS-COV-2 RELATED MYOCARDITIS}

There are only case reports in the literature about SARSCoV-2 related myocarditis. Hence the beginning of SARS-CoV-2 outbreak is recent, there are not enough trials and data about the treatment of SARS-CoV-2 related myocarditis. Therefore; there are not any specific treatment options for SARS-CoV-2 related myocarditis and management is based on constitutively traditional viral myocarditis treatment.

\section{Heart failure therapy}

Most of the cases with viral myocarditis are asymptomatic and heart failure develops in a small proportion of cases. ${ }^{56}$ Patients with heart failure or wall motion abnormality should be treated by the lights of current heart failure gudelines to prevent from irreversible myocardial remodelling. ${ }^{57}$ ACEIs and ARBs are the indispensible part of the treatment. In mice and rat models; it is demonastrated that kaptopril, olmesartan and losartan reduced inflammation, necrosis, and fibrosis in experimental virus induced myocarditis models. ${ }^{58,59}$

Diuretics should be used in patients with the symptoms and signs of hypervolemia. Torsemide has additional beneficial effects than furosemide. Torsemide reduced the progression of myocarditis in a rat model by decreasing fibrosis, myocyte sizes, and myocardial protein levels of transforming growth factor-beta-1, collagen III, and aldosterone synthase. ${ }^{60}$

Beta-blockers improveventricular function and reduce hospital admission due to worsening heart failure. Usage of beta-blockers in myocarditis is associated with better survival and it is known that lack of beta-blocker treatment is associated with poor outcomes. ${ }^{61}$ Carvedilol has antioxidant properties in addition to its beta receptor blocking effect and it is shown that carvedilol decreases inflammatory response in experimental rat models while metoprolol and propronalol did not havesuch immunomodulating effects. ${ }^{62}$ On the contrary; metoprolol administration significantly increased inflammation and necrosis as well as mortality in murines with Coxsackievirus B3 myocarditis. ${ }^{63}$ Beta-blocker 
treatment should be avoided in patients with hemodynamic instablity and acute decompansated heart failure. ${ }^{57}$

Aldosterone antagonists are recommended in patients with heart failure whose functional capacity is still NYHA II-IV despite treatment with beta blocker and ACE/ARB combination. Aldosterone antagonists reduce recurrent hosptalisation and improve survival rate in heart failure with reduced EF. ${ }^{57}$ Eplerenone has additional anti-inflammatory effects by inhibiting mast cell-derived proteinases. ${ }^{64}$ Aldosterone antagonists should not be administered in ealy phases of myocarditis and it should be considered if firstline heart failure treatment failed.

Cardiac glycosides are used in patients with HF to improve functional capacity and reduce rehospitalization. However, glycosides causes increase in myocardial work and exaggeretes production of myocardial pro-inflammatory cytokines. Glycosides may also limit the maximal tolerated beta blocker dose. ${ }^{65}$ Therefore, cardiac glycosides should be avoided in patients with myocarditis.

Calcium channel blockers are not recommended in heart failure due to their negative inotropic effects. In mice models amlodipine reduced nitric oxide levels resulting with decreased myocardial damage. In another animal study including rats with experimental autoimmune myocarditis, pranidipine and amlodipine improved left ventricular functions. ${ }^{6,67}$

Non-steroidal antiinflammatory drugs are mainstay of pericarditis treatment but they should be avoided in viral myocarditis. Indomethacin and NSAIDs caused increased inflammation and mortality rates in murine models of acute viral myocarditis. ${ }^{68,69}$ Asetylsalicylic acid administration is also shown to be associated with increased mortality. ${ }^{70}$

\section{Restriction of physical activity}

Aerobic physical activity should be avoided in patients with acute myocarditis. Sustained exercise leads both immunsupression by inhibiting $\mathrm{T}$ cell functions and increased mortality. ${ }^{71}$ Duration of the activity restriction should last till the disease completely resolved. Physical activity should be delayed at least 6 months and physical activity should be permitted after detailed cardiologic evaluation in elite athletes. ${ }^{72}$

\section{Arrhythmia management}

All types of arrhythmias may develop during acute myocarditis. Advanced atrioventricular (AV) blocks and symptomatic bradycardia episodes should be treated with temporary pacemaker implantation. Complete heart block or ongoing advanced AV block despite the resolution of acute phase of myocarditis are indications of pacemaker implantation. ICD (Implantable Cardioverter Defibrillator) implantation should be considered in patients without documented malignant arrhythmia if the functional capacity is NYHA II-IV and LVEF $<35 \%$ despite 3 months of optimal medical treatment. In patients with cardiac arrest due to ventricular tachycardia or fibrillation, ICD implantation should be offered. Followup with lifevest during the acute episode and re-assessment of ICD requirement is another alternative option in patients with documented VT/VF episode. ${ }^{73}$

\section{Immunmodulatory treatment \\ Antiviral Therapies}

There are conflicting data about the use of antiviral agents in acute myocarditis. Pleconaril prevents the enterovirus from exposing its RNA, and in rhinoviruses Pleconaril prevents the virus from attaching itself to the host cell. ${ }^{74} \mathrm{It}$ is demonstrated that Pleconaril may have beneficial effects if it is administered in the early phase of the disease. ${ }^{75}$ Acyclovir, gancyclovir and valgancyclovir can be used in Herpes virüs related viral myocarditis. ${ }^{76}$ There are several drugs used to treat SARS-CoV-2 infection but all of them are administered experimentally and only some of them found to be effective by small population based studies.

\section{Intravenous Immunglobulin}

Immunglobulins have antiviral and immunmodulation effects. In children with acute myocarditis, high dose inravenous immunglobulin (IVIG) caused improvement in left ventricular functions and survival rates oneyear after administration. ${ }^{77}$ Gullestad L et al., demonstrated that IVIG treatment elicits increase in LV ejection fraction in patients with symptomatic chronic heart failure patients. However; in another study IVIG had no beneficial effects on recent onset dilated cardiomyopathy due to biopsy proven viral myocarditis. ${ }^{78}$

IVIG use was reported in two cases of SARS-CoV-2 related myocarditis. IVIG was combined with steroid in one patient and combined with steroid and interferon- 1 beta in another patient. Both of the patients recovered from the disaese and LV functions were improved after treatment. ${ }^{79}$

\section{Immunoadsorption}

The aim of Immunoadsorption is to remove antibodies damaging heart from blood. Immunoadsorption decreases myocardial inflammation and is associated with improvement in hemodynamic paramaters including cardiac stroke volume. ${ }^{80}$ A randomized study with dilated cardiomyopathy patients have shown that immunoadsorption improves LV functions and decreased myocardial inflammation. ${ }^{81}$

\section{Interferon- 1 beta}

Interferons (IFN) serve as a defense against most of viral infections. There are strong datase about use of interferons in rheumatic disease due to their immunomodulating 
effects, there are limited datas about their administration in viral myocarditis. Efficacy of interferon beta-1a was assessed in patients with persistent adenovirus and enterovirus infection of myocardium and after 6 months of treatment; viral genomes were completely eliminated from myocardium and NYHA class was improved and heart failure related symptoms decreased significantly. ${ }^{82}$ However, the beneficial effects of IFN-beta was observed to be less in Parvovirus and Herpes virüs associated myocarditis than enterovirus and adenovirus related myocarditis. Interferons are administered subcutaneously and have side effects including fatigue, influenza-like symptoms and inection site reactions. It should be noted that heart failure symptoms may worsen and LV functions may get worse between the $4^{\text {th }}$ and $12^{\text {th }}$ weeks of the treatment and it usually resolves 1-2 weeks later. ${ }^{83}$ BICC study including 143 patients with viral myocarditis related dilated cardiomyopathy demonstrated that IFN-beta treatment is associated with significant reduction of viral genom in patients with entovirus infection while complete elimination could not be achieved in patients with Parvovirus B19 infection. It was also established that despite there were not significant change in LV parameters; only patient global assessment and NYHA functional class were improved. ${ }^{84}$

\section{Immunsupressive treatment}

Efficacy of prednisone was demonstrated in a randomised controlled trial in 1989. Steroid treatment resulted with higher LV ejection fraction and lower LV diameters in patients with dilated cardiomyopathy. ${ }^{85}$ In another randomized trial; 3 months of treatment with corticosteroid and azathioprine combination improved LV parameters and heart failure symptoms in 41 patients with biopsy proven immune myocarditis. ${ }^{86}$ TIMIC study included cases with virus negative inflammatory myocarditis and the study demonstrated that patients with azathioprine and prednisone treatment had better LVEF functions and functional capacity after 6 months follow up, while patients who underwent placebo arm had worse left ventricular functions after follow-up period. ${ }^{87}$

\section{CURRENT DATA ABOUT THE MEDICAL TREATMENT OF SARS-COV-2 RELATED MYOCARDITIS}

There are not any specific antiviral agent for SARS-CoV-2 but some drugs were shown to be effective in treatment of SARS-CoV-2 infection. Hydroxychloroquine, lopinavir/ ritonavir, azithromycin, ivermectin, favipravir and remdesivir are some of the drugs that may have beneficial effects during SARS-CoV-2 infection. There are only case reports about SARS-CoV-2 related myocarditis. The cases reported with detailed treatment protocols are summarized in Table-1. The reported cases are severe cases with significant left ventricular dysfunction and cardiogenic shock. Most of the myocarditis cases usually have mild symptoms so probably the detected cases are just the tip of the iceberg.

Zeng JH et al. reported a 63 year old male patients with cardiogenic shock due to SARS-CoV-2 related myocarditis. His LVEF was $32 \%$ and the patient was transferred into intensive care unit due to fulminant myocarditis. Lopinavir/ ritonavir, interferon alfa, steroid and IVIG were administered in addition to supportive care. Left ventriclar functions improved and patient recovered from myocarditis. ${ }^{88}$ In another case report; a 37 year old male presented with fulminant myocarditis due to SARS-CoV-2 infection. Steroid and IVIG combination was administered in the early stage of the disease. Patient recovered from the disease one week later and discharged without any complications.

In the reported cases, methylprednisolone was used in 3 patients. The most common used antiviral agent was lopinavir/ritonavir and it was used in 3 patients. Hydroxychloroquine was used in two patients and IVIG was administered in two patients. IFN-beta was used only in one patient. All of the patients were recovered from myocarditis successfully (Table- 1 ). ${ }^{79,89}$

Tocilizumab is an antibody against IL-6 receptor and is widely used in rheumatologic diseases. Tocilizumab was administered in some severe SARS-CoV-2 infection cases with ARDS, refractory shock, refractory fever or significantly high inflammatory markers and satisfactory resuls were obtained. ${ }^{90}$

\section{TAKE HOME MESSAGES}

- The obvious relationship between TnT levels and C-reactive protein and N-terminal pro-B-type natriuretic peptide levels indicates that myocardial injury is associated with the severity of inflammation and ventricular dysfunction.

- ACE inhibitors or ARBs should be administered in patients with wall motion abnormality or heart failure with reduced EF.

- Diuretics should be considered in patients with volume overload and torsemide should be preferred as first option.

- Beta blockers should be administered if patient had no contraindications such as bradycardia, acute decompansated heart failure, advanced AV block and carvedilol should be preferred. Metoprolol should be avoided.

- Non-steroidal antiinflammatory drugs and cardiac glycosides should be avoided.

- Physical activity should be restricted until the disease resolved. 


\section{Table 1:Treatment of Patients with SARS-CoV-2 Related Myocarditis}

\begin{tabular}{|c|c|c|c|c|}
\hline $\begin{array}{l}\text { Patient No } \\
\text { (Age/Gender) Country }\end{array}$ & Symptoms & Baseline ECG/Echo & Treatment & Outcome \\
\hline $\begin{array}{l}\text { Case } 1 \\
\text { (37/Male) } \\
\text { China }\end{array}$ & $\begin{array}{l}{ }^{*} \text { Chest pain, } \\
\text { dyspnea }\end{array}$ & $\begin{array}{l}\text { * ST elevation in inferior } \\
\text { leads } \\
\text { * LV EDD: } 58 \mathrm{~mm} \\
\text { * LV EF: } 27 \% \\
\text { *Minimal pericardial } \\
\text { effusion }\end{array}$ & $\begin{array}{l}\text { *Methylprednizolone } 200 \text { mg/day } \\
\text { (4 days) } \\
\text { *IVIG } 20 \text { g/day (4 days) } \\
\text { * Noradrenaline/milrinone } \\
\text { * Torsemide } \\
\text { * Piperacillin-tazobactam }\end{array}$ & $\begin{array}{l}\text { *LV EF: } 66 \% \text { (1 week } \\
\text { later) } \\
\text { * Significant decrease in } \\
\text { cardiac biomarkers }\end{array}$ \\
\hline $\begin{array}{l}\text { Case } 3 \\
\text { (53/Female) } \\
\text { Italy }\end{array}$ & $\begin{array}{l}{ }^{*} \text { Fever, cough, } \\
\text { fatigue }\end{array}$ & $\begin{array}{l}\text { *Low voltage in extremity } \\
\text { leads } \\
\text { * ST depression in V1 } \\
\text { and aVR } \\
{ }^{*} \text { LV EF: } 40 \% \\
\text { * Moderate pericardial } \\
\text { effusion } \\
\text { * Mild diastolic } \\
\text { dysfunction }\end{array}$ & $\begin{array}{l}\text { * Dobutamine (4 days) } \\
\text { * Canrenone } 1 \times 50 \mathrm{mg} \\
\text { * } \text { Furosemide } \\
\text { * Bisoprolol } 1 \times 2.5 \mathrm{mg} \\
\text { * Methylprednizolone } 1 \mathrm{mg} / \mathrm{kg} / \text { day } \\
\text { (3 days) } \\
\text { *Hydroxychloroquine } 2 \times 200 \mathrm{mg} \\
\text { * Lopinavir/ritonavir } 2 \times 500 \mathrm{mg} \\
\text { * Aspirin } 2 \times 500 \mathrm{mg}\end{array}$ & $\begin{array}{l}{ }^{*} \text { LV EF: } 44 \% \text { (6 days } \\
\text { later) } \\
{ }^{*} \text { Significant decrease in } \\
\text { cardiac biomarkers and } \\
\text { pericardial effusion }\end{array}$ \\
\hline $\begin{array}{l}\text { Case } 4 \\
\text { (43/Female) } \\
\text { Italy }\end{array}$ & ${ }^{*}$ Fever, chest pain & $\begin{array}{l}\text { * Low atrial rhythm } \\
\text { * ST elevation in V1-2 } \\
\text { and aR } \\
{ }^{*} \text { U waves } \\
\text { * LVE EF: } 43 \% \\
\text { * Inferolateral wall } \\
\text { hypokinesia }\end{array}$ & $\begin{array}{l}\text { *Hydroxychloroquine } 2 \times 200 \mathrm{mg} \\
\text { * Lopinavir/ritonavir } 2 \times 500 \mathrm{mg} \\
\text { * CPAP (NIMV) }\end{array}$ & $\begin{array}{l}\text { *LV EF: } 65 \% \\
\text { * Significant decrease in } \\
\text { cardiac biomarkers }\end{array}$ \\
\hline
\end{tabular}

- IVIG and interferon therapy are feasible treatment options with reasonable side effect profile.

- Patients requiring V-A ECMO support who incidentally test positive for COVID-19 but are not thought to be critically ill due to the virus should be considered for ECMO support in the usual fashion.

\section{REFERENCES}

1. Zhou $P$, Yang XL, Wang XG, Wang X, Hu B, Zhang L, et al. Pneumonia outbreak associated with a new coronavirus of probable bat origin. Nature. 2020; 579:270-273.

https://doi.org/10.1038/s41586-020-2012-7

2. WHO Director-General's opening remarks at the media briefing on COVID-19. World Health Organization, 2020. https://www.who.int/dg/speeches/detail/who-direc torgeneral-s-opening-remarks-at-the-media-briefing-oncovid-19 (11 March 2020).

3. Lu R, Zhao X, Li J, Niu P, Yang B, Wuet H, et al. Genomic characterisation and epidemiology of 2019 novel coronavirus: implications for virus origins and receptor binding. Lancet. 2020; 395(10224):565-574.

https://doi.org/10.1016/S0140-6736(20)30251-8

4. Huang C, Wang Y, Li X, Ren L, Zhao J, Hu Y, et al. Clinical features of patients infected with 2019 novel coronavirus in Wuhan, China. Lancet. 2020; 395(10223):497-506.

https://doi.org/10.1016/S0140-6736(20)30183-5

5. Guan WJ, Ni ZY, Hu Y, Liang WH, Ou CQ, He JX, et al.
China Medical Treatment Expert Group for Covid-19. Clinical characteristics of coronavirus disease 2019 in China. N Engl J Med. 2020; 382:1708-1720.

https://doi.org/10.1056/NEJMoa2002032

6. Badawi A and Ryoo SG. Prevalence of comorbidities in the Middle East respiratory syndrome coronavirus (MERS-CoV): a systematic review and meta-analysis. Int J Infect Dis. 2016; 49:129-133.

https://doi.org/10.1016/j.ijid.2016.06.015

7. Wu Z and McGoogan JM. Characteristics of and important lessons from the coronavirus disease 2019 (COVID-19) outbreak in China: summary of a report of 72314 cases from the Chinese Center for Disease Control and Prevention. JAMA. 2020; 323(13):1239-1242.

https://doi.org/10.1001/jama.2020.2648

8. Wang D, Hu B, Hu C, Zhu F, Liu X, Zhang J, et al. Clinical characteristics of 138 hospitalized patients with 2019 novel coronavirus-infected pneumonia in Wuhan, China. JAMA. 2020; 323: 1061-1069.

https://doi.org/10.1001/jama.2020.1585

9. Zhou F, Yu T, Du R, Fan G, Liu Y, Liuet Z, et al. Clinical course and risk factors for mortality of adult inpatients with COVID-19 in Wuhan, China: a retrospective cohort study. Lancet. 2020; 395: 1054-1062. https://doi.org/10.1016/S0140-6736(20)30566-3

10. Shi S, Qin M, Shen B, Cai Y, Liu T, Yang F, et al. Cardiac injury in patients with corona virus disease 2019. JAMA Cardiol. 2020; 5(7):802-810. https://doi.org/10.1001/jamacardio.2020.0950

11. Chen C, Chen C, Yan JT, Zhou N, Zhao JP and Wang DW. 
Analysis of myocardial injury in patients with COVID-19 and association between concomitant cardiovascular diseases and severity of COVID-19. Zhonghua Xin Xue Guan Bing Za Zhi. 2020;48(0):E008.

12. Guo T, Fan $Y$, Chen M, Wu X, Zhang L, He T, et al. Cardiovascular implications of fatal outcomes of patients with coronavirus disease 2019 (COVID-19). JAMA Cardiol. 2020; 5(7):811-818. https://doi.org/10.1001/jamacardio.2020.1017

13. National Center for Immunization and Respiratory Diseases (NCIRD), Division of Viral Diseases.

14. World Health Organization. Novel coronavirus - China. Jan 12, 2020. http://www.who.int/csr/don/12-january-2020-novelcoronavirus-china/en/(accessed Jan 19, 2020).

15. Zhu N, Zhang D, Wang W, Li X, Yang B, Song J, et al. A novel coronavirus from patients with pneumonia in China, 2019. N Engl J Med. 2020; 382:727-733.

https://doi.org/10.1056/NEJMoa2001017

16. World Health Organization. Director-General's remarks at the media briefing on 2019-nCoV on 11 February 2020. https://www. who.int/dg/speeches/detail/who-director-general-s-remarks-atthe-media-briefing-on-2019-ncov-on-11-february-2020.

17. Lessler J, Reich NG, Brookmeyer R, Perl TM, Nelson KE and Cummings DA. Incubation periods of acute respiratory viral infections: a systematic review. Lancet Infect Dis. 2009; 9(5):291-300. https://doi.org/10.1016/S1473-3099(09)70069-6

18. Li Q, Guan X, Wu P, Wang X, Zhou L, Tong Y, et al. Early transmission dynamics in Wuhan, China, of novel coronavirusinfected pneumonia. N Engl J Med. 2020; 382(13):1199-1207. https://doi.org/10.1056/NEJMoa2001316

19. Backer JA, Klinkenberg $D$ and Wallinga J. Incubation period of 2019 novel coronavirus (2019-nCoV) infections among travellers from Wuhan, China, 20-28 January 2020. Euro Surveill. 2020; 25(5): pii=2000062.

https://doi.org/10.2807/1560-7917.ES.2020.25.5.2000062

20. Centers for Disease Control and Prevention. Coronavirus disease 2019 (COVID-19). Accessed February 22, 2020. https:// www.cdc.gov/coronavirus/2019 ncov/about/symptoms.html.

21. Yeo $C$, Kaushal $S$ and Yeo D. Enteric involvement of coronaviruses: is faecal-oral transmission of SARS-CoV-2 possible? Lancet Gastroenterol Hepatol. 2020; 5(4):335-337. https://doi.org/10.1016/S2468-1253(20)30048-0

22. Corman VM, Eckerle I, Bleicker T, Zaki A, Landt O, EschbachBludau M, et al. Detection of a novel human coronavirus by real-time reverse-transcription polymerase chain reaction. Euro Surveill. 2012; 17(39):pii=20285.

https://doi.org/10.2807/ese.17.39.20285-en

23. Rui A and Guzik TJ. Inside the heart of COVID-19. Cardiovascular Research. 2020; 116(6): e59-e61. https://doi.org/10.1093/cvr/cvaa086

24. Yan R, Zhang Y, Li Y, Xia L, Guo Y, Zhou Q, et al. Structural basis for the recognition of SARS-CoV-2 by full-length human ACE2. Science. 2020; 367(6485):1444-1448.

https://doi.org/10.1101/2020.02.19.956946

25. Zhang $\mathrm{H}$, Penninger JM, Li $\mathrm{Y}$, Zhong $\mathrm{N}$ and Slutsky AS. Angiotensin-converting enzyme 2 (ACE2) as a SARS-CoV-2 receptor: molecular mechanisms and potential therapeutic target. Intensive Care Med. 2020; 46:586-590. https://doi.org/10.1007/s00134-020-05985-9

26. Hashimoto $T$, Perlot $T$, Rehman $A$, Trichereau $J$, Ishiguro $H$, Paolino M, et al. ACE2 links amino acid malnutrition to microbial ecology and intestinal inflammation. Nature. 2012; 477-481. https://doi.org/10.1038/nature11228

27. Chen L, Li X, Chen M, Feng $Y$ and Xiong C. The ACE2 expression in human heart indicates new potential mechanism of heart injury among patients infected with SARS-CoV-2. Cardiovascular Research.2020; 116(6):1097-1100. https://doi.org/10.1093/cvr/cvaa078

28. Xu Z, Shi L, Wang Y, Zhang J, Huang L, Zhang C, et al. Pathological findings of COVID-19 associated with acute respiratory distress syndrome. Lancet Respir Med. 2020; 8(4): 420-422. https://doi.org/10.1016/S2213-2600(20)30076-X

29. Yang X, Yu Y, Xu J, Shu H, Xia J, Liu H, et al. Clinical course and outcomes of critically ill patients with SARS-CoV-2 pneumonia in Wuhan, China: a single-centered, retrospective, observational study. Lancet Respir Med. 2020; 8(5):475-481. https://doi.org/10.1016/S2213-2600(20)30079-5

30. Ruan $Q$, Yang K, Wang W, Jiang $L$ and Song J. Clinical predictors of mortality due to COVID-19 based on an analysis of data of 150 patients from Wuhan, China. Intensive Care Med. 2020; 46:846-848. https://doi.org/10.1007/s00134-020-05991-x

31. Tang N, Li D, Wang $X$ and Sun Z. Abnormal Coagulation parameters are associated with poor prognosis in patients with novel coronavirus pneumonia. J Thromb Haemost. 2020; 18: 844-847. https://doi.org/10.1111/jth.14768

32. Fan BE, Chong VCL, Chan SSW, Lim GH, Lim KGE, Tan $\mathrm{GB}$, et al. Hematologic parameters in patients with COVID-19 infection. Am J Hematol. 2020; 95(6):E131-E134. https://doi.org/10.1002/ajh.25774

33. Libby $P$ and Simon DI. Inflammation and thrombosis: the clot thickens. Circulation. 2001; 103:1718-1720. https://doi.org/10.1161/01.CIR.103.13.1718

34. Bonow RO, Fonarow GC, O'Gara PT and Yancy CW. Association of Coronavirus Disease 2019 (COVID-19) With Myocardial Injury and Mortality. JAMA Cardiol. 2020; 5(7):751-753. https://doi.org/10.1001/jamacardio.2020.1105

35. Oudit GY, Kassiri Z, Jiang C, Liu PP, Poutanen SM, Penninger JM, et al. SARS-coronavirus modulation of myocardial ACE2 expression and inflammation in patients with SARS. Eur J Clin Invest. 2009; 39(7):618-625. https://doi.org/10.1111/j.1365-2362.2009.02153.x

36. Islam KU and Iqbal J. An Update on Molecular Diagnostics for COVID-19. Front Cell Infect Microbiol. 2020;10:560616. https://doi.org/10.3389/fcimb.2020.560616

37. Xu X, Chen P, Wang J, Feng J, Zhou H, Li X, et al. Evolution of the novel coronavirus from the ongoing Wuhan outbreak and modeling of its spike protein for risk of human transmission. Sci China Life Sci. 2020; 63(3):457-460. https://doi.org/10.1007/s11427-020-1637-5

38. Wang $W, X u$ Y, Gao R, Lu R, Han K, Wu G, et al. Detection of SARS-CoV-2 in different types of clinical specimens. JAMA. 2020;323(18):1843-1844. https://doi.org/10.1001/jama.2020.3786

39. Crackower MA, Sarao R, Oudit GY, Yagil C, Kozieradzki I, Scanga SE, et al. Angiotensin converting enzyme 2 is an essential regulator of heart function. Nature. 2002; 417:822-828. https://doi.org/10.1038/nature00786

40. Driggin E, Madhavan MV, Bikdeli B, Driggin E, Chuich T, Laracy $\mathrm{J}$, et al. Cardiovascular Considerations for Patients, Health Care Workers, and Health Systems During the Coronavirus Disease 2019 (COVID-19) Pandemic. J Am Coll Cardiol. 2020;75(18):2352-2371. 
https://doi.org/10.1016/j.jacc.2020.03.031

41. Fung G, Luo H, Quu Y, Yang D and McManus B. Myocarditis. Circ Res. 2016;118(3):496-514. https://doi.org/10.1161/CIRCRESAHA.115.306573

42. Esfandiarei $M$ and McManus BM. Molecular biology and pathogenesis of viral myocarditis. Annu Rev Pathol. 2008; 3:127-155.

https://doi.org/10.1146/annurev.pathmechdis.3.121806.151534

43. Zheng YY, Ma YT, Zhang JY and Xie X. COVID-19 and the cardiovascular system. Nat Rev Cardiol. 2020; 17(5):259-260. https://doi.org/10.1038/s41569-020-0360-5

44. $\mathrm{Hu} \mathrm{H}, \mathrm{Ma} F$, Wei $X$ and Fang $\mathrm{Y}$. Coronavirus fulminant myocarditis saved with glucocorticoid and human immunoglobulin. Eur Heart J. 2021;42(2):206.

https://doi.org/10.1093/eurheartj/ehaa190

45. Inciardi RM, Lupi L, Zaccone G, Italia L, Raffo M, Tomasoniet D, et al. Cardiac Involvement in a Patient With Coronavirus Disease 2019 (COVID-19). JAMA Cardiol. 2020; 5(7):819-824.

https://doi.org/10.1001/jamacardio.2020.1096

46. Lu H, Stratton CW and Tang YW. Outbreak of pneumonia of unknown etiology in Wuhan China: the mystery and the miracle [published January 16, 2020]. J Med Virol. 2020; 92(4):401-402. https://doi.org/10.1002/jmv.25678

47. Hosseiny M, Kooraki S, Gholamrezanezhad A, Reddy S and Myers L. Radiology perspective of coronavirus disease 2019 (COVID-19): Lessons from severe acute respiratory syndrome and Middle East Respiratory Syndrome. AJR Am J Roentgenol. 2020;1-5:1-5.

https://doi.org/10.2214/AJR.20.22969

48. Sala S, Peretto G, Gramegna M, Palmisano A, Villatore A, Vignale $D$, et al. Acute myocarditis presenting as a reverse Tako-Tsubo syndrome in a patient with SARS-CoV-2 respiratory infection. Eur Heart J. 2020;41(19):1861-1862.

https://doi.org/10.1093/eurheartj/ehaa286

49. Tavazzi G, Pellegrini C, Maurelli M, Belliato M, Sciutti F, Bottazzi A, et al. Myocardial localization of coronavirus in COVID-19 cardiogenic shock. Eur J Heart Fail. 2020; 22(5):911-915. https://doi.org/10.1002/ejhf.1828

50. Liu P and Baughman LK. Myocarditis. Braunwald's Heart Disease: A Textbook of Cardiovascular Medicine, International Edition Chapter 701595-1610.

51. Xu Z, Shi L, Wang Y, Zhang J, Huang L, Zhang C, et al. Pathological findings of COVID-19 associated with acute respiratory distress syndrome. Lancet Respir Med. 2020;8(4):420-422. https://doi.org/10.1016/S2213-2600(20)30076-X

52. Bennett MK and Tang WHW. Myocarditis. Manual of Cardiovascular Medicine. Fourth Edition 176-199.

53. Caforio AL, Pankuweit S, Arbustini E, Basso C, GimenoBlanes J, Felix SB, et al. Current state of knowledge on aetiology, diagnosis, management, and therapy of myocarditis: a position statement of the European Society of Cardiology Working Group on Myocardial and Pericardial Diseases. Eur Heart J. 2013;34(33):2636-2648. 2648a-2648d. https://doi.org/10.1093/eurheartj/eht210

54. Caforio AL. Cardiac complications in COVID-19: Myocarditis. https://www.escardio.org/Education/COVID-19-andCardiology?hit=home\&urlorig=/vgn-ext-templating

55. Guo T, Fan Y, Chen M, Wu X, Zhang L, He T, et al. Cardiovascular implications of fatal outcomes of patients with coronavirus disease 2019 (COVID-19). JAMA Cardiol. 2020;5(7):811-818. https://doi.org/10.1001/jamacardio.2020.1017
56. D’Ambrosio A, Patti G, Manzoli A, Sinagra G, Di Lenarda A, Silvestri $F$, et al. The fate of acute myocarditis between spontaneous improvement and evolution to dilated cardiomyopathy: a review. Heart. 2001;85(5):499-504. https://doi.org/10.1136/heart.85.5.499

57. Dickstein K, Cohen-Solal A, Filippatos G, McMurray JJ, Ponikowski P, Poole-Wilson PA, et al. ESC Guidelines forthe diagnosis and treatment of acute and chronic heart failure 2008:the Task Force for the Diagnosis and Treatment of Acute and Chronic Heart Failure 2008 of the European Society of Cardiology. Eur Heart J. 2008;29:2388-2442.

https://doi.org/10.1016/j.ejheart.2008.08.005

58. Godsel LM, Leon JS, Wang K, Fornek JL, Molteni A and Engman DM. Captopril prevents experimental autoimmune myocarditis. J Immunol. 2003;171(1):346-352. https://doi.org/10.4049/jimmunol.171.1.346

59. Bahk TJ, Daniels MD, Leon JS, Wang K and Engman DM. Comparison of angiotensin converting enzyme inhibition and angiotensin II receptor blockade for the prevention of experimental autoimmune myocarditis. Int J Cardiol. 2008;125:85-93. https://doi.org/10.1016/j.ijcard.2007.04.062

60. Veeraveedu PT, Watanabe K, Ma M, Palaniyandi SS, Yamaguchi K, Suzuki K, et al. Torasemide, a longacting loop diuretic, reduces the progression of myocarditis to dilated cardiomyopathy. Eur J Pharmacol. 2008;581:121-131. https://doi.org/10.1016/j.ejphar.2007.11.034

61. Kindermann I, Kindermann M, Kandolf R, Klingel K, Bültmann B, et al. Predictors of outcome in patients with suspected myocarditis. Circulation. 2008;118(6):639-648. https://doi.org/10.1161/CIRCULATIONAHA.108.769489

62. Yuan Z, Shioji K, Kihara Y, Takenaka H, Onozawa $Y$ and Kishimoto C. Cardioprotective effects of carvedilol on acute autoimmune myocarditis: anti-inflammatory effects associated with antioxidant property. Am J Physiol Heart Circ Physiol. 2004;286(1):H83-H90. https://doi.org/10.1152/ajpheart.00536.2003

63. Rezkalla S, Kloner RA, Khatib G, Smith FE and Khatib R. Effect of metoprolol in acute coxsackievirus B3 murine myocarditis. J Am Coll Cardiol. 1988;12(2):412-414. https://doi.org/10.1016/0735-1097(88)90414-7

64. Xiao J, Shimada M, Liu W, Hu D and Matsumori A. Antiinflammatory effects of eplerenone on viral myocarditis. Eur J Heart Fail. 2009;11(4):349-353. https://doi.org/10.1093/eurjhf/hfp023

65. Matsumori A, Igata H, Ono K, Iwasaki A, Miyamoto T, Nishio R, et al. High doses of digitalis increase the myocardial production of proinflammatory cytokines and worsen myocardial injury in viral myocarditis: a possible mechanism of digitalis toxicity. Jpn Circ J. 1999;63(12):934-940. https://doi.org/10.1253/jcj.63.934

66. Wang WZ, Matsumori A, Yamada T, Shioi T, Okada I, Matsui S, et al. Beneficial effects of amlodipine in a murine model of congestive heart failure induced by viral myocarditis. A possible mechanism through inhibition of nitric oxide production. Circulation. 1997;95:245-251.

https://doi.org/10.1161/01.CIR.95.1.245

67. Veeraveedu PT, Watanabe K, Ma M, Gurusamy N, Palaniyandi SS, Wen J, et al. Comparative effects of pranidipine with amlodipine in rats with heart failure. Pharmacology. 2006;77:1-10. https://doi.org/10.1159/000091746

68. Costanzo-Nordin MR, Reap EA, O'Connell JB, Robinson JA and Scanlon PJ. A nonsteroid anti-inflammatory drug exacerbates Coxsackie B3 murine myocarditis. J Am Coll Cardiol. 
1985;6(5):1078-1082.

https://doi.org/10.1016/S0735-1097(85)80312-0

69. Khatib R, Reyes MP, Smith F, Khatib G and Rezkalla S. Enhancement of coxsackievirus B4 virulence by indomethacin. J Lab Clin Med. 1990;116:116-120.

70. Liu PP and Mason JW. Advances in understanding of myocarditis. Circulation. 2001;104(9):1076-1082.

https://doi.org/10.1161/hc3401.095198

71. Cabinian AE, Kiel RJ, Smith F, Ho KL, Khatib R and Reyes MP. Modification of exercise-aggravated coxsackievirus B3 murine myocarditis by $\mathrm{T}$ lymphocyte suppression in an inbred model. $\mathrm{J}$ Lab Clin Med. 1990;115:454-462.

72. Khatib R, Reyes MP, Khatib $G$ and Giraldo A. The effects of pre-existing coxsackievirus B4 myocardial disease on the expression of coxsackievirus B3 myocarditis. The Canadian Journal of Cardiology. 1993;9(5):444-447.

73. Kindermann I, Barth C, Mahfoud F, Ukena C, Lenski M, Yilmaz A, et al. Update on Myocarditis. J Am Coll Cardiol. 2012;59(9):779-792. https://doi.org/10.1016/j.jacc.2011.09.074

74. Florea $\mathrm{N}$, Maglio $\mathrm{D}$ and Nicolau D. Pleconaril, a novel antipicornaviral agent. Pharmacotherapy. 2003;23(3):339-348. https://doi.org/10.1592/phco.23.3.339.32099

75. Schultheiss HP and Kuehl U. Cardiovascular viral infections. Lennette's Laboratory Diagnosis of Viral Infections, Chapter 18. 4th ed. New York: Informa Healthcare USA Inc; 2010, p304-p318.

76. Krueger GRF and Ablashi DV. Human Herpesvirus-6: A Short Review of Its Biological Behavior. Intervirology. 2003;46(5):257-269. https://doi.org/10.1159/000073205

77. Drucker NA, Colan SD, Lewis AB, Beiser AS, Wessel DL, Takahashi M, et al. Gamma-globulin treatment of acute myocarditis in the pediatric population. Circulation. 1994;89:252-257.

https://doi.org/10.1161/01.CIR.89.1.252

78. Caforio AL, Calabrese F, Angelini A, Tona F, Vinci A, Bottaro S, et al. A prospective study of biopsy-proven myocarditis: prognostic relevance of clinical and aetiopathogenetic features at diagnosis. Eur Heart J. 2007;28(11):1326-1333.

https://doi.org/10.1093/eurheartj/ehm076

79. Aktoz M, Altay H, Aslanger E, Atalar E, Aytekin V, Baykan AO, et al. Consensus Report from Turkish Society of Cardiology: COVID-19 and Cardiovascular Diseases. What cardiologists should know. (25th March 2020). Turk Kardiyol Dern Ars. 2020;48(Suppl 1):1-48.

https://doi.org/10.5543/tkda.2020.97198

80. Doesch AO, Konstandin M, Celik S, Kristen A, Frankenstein L, Hardt $S$, et al. Effects of protein $A$ immunoadsorption in patients with advanced chronic dilated cardiomyopathy. J Clin Apher. 2009;24(4):141-149. https://doi.org/10.1002/jca.20204

81. Felix SB, Staudt A, Landsberger M, Grosse Y, Stangl V, Spielhagen $\mathrm{T}$, et al. Removal of cardiodepressant antibodies in dilated cardiomyopathy by immunoadsorption. J Am Coll Cardiol. 2002;39(4):646-652. https://doi.org/10.1016/S0735-1097(01)01794-6

82. Kuhl $U$, Pauschinger $M$, Schwimmbeck PL, Seeberg B, Lober C, Noutsias M, et al. Interferon-beta treatment eliminates cardiotropic viruses and improves left ventricular function in patients with myocardial persistence of viral genomes and left ventricular dysfunction. Circulation. 2003;107: 2793-2798.

https://doi.org/10.1161/01.CIR.0000072766.67150.51

83. Schultheiss HP, Kühl $U$ and Cooper LT. The management of myocarditis. Eur Heart J. 2011;32(21):2616-2625.

https://doi.org/10.1093/eurheartj/ehr165

84. Schultheiss HP, Piper $C$ and Sowade $K$. The effect of subcutaneous treatment with interferon-beta-1b over 24 weeks on safety, virus elimination and clinical outcome in patients with chronic viral cardiomyopathy. Circulation.2008; 118(22).

85. Parrillo JE, Cunnion RE, Epstein SE, Parker MM, Suffredini AF, Brenner $\mathrm{M}$, et al. A prospective, randomized, controlled trial of prednisone for dilated cardiomyopathy. N Engl J Med. 1989;321(16):1061-1068.

https://doi.org/10.1056/NEJM198910193211601

86. Wojnicz R, Nowalany-Kozielska E, Wojciechowska C, Glanowska G, Wilczewski P, Niklewski T, et al. Randomized, placebo-controlled study for immunosuppressive treatment of inflammatory dilated cardiomyopathy: two-year follow-up results. Circulation. $2001 ; 104(1): 39-45$.

https://doi.org/10.1161/01.CIR.104.1.39

87. Frustaci A, Russo MA and Chimenti C. Randomized study on the efficacy of immunosuppressive therapy in patients with virus-negative inflammatory cardiomyopathy: the TIMIC study. Circulation. 2008;118:667-671.

https://doi.org/10.1093/eurheartj/ehp249

88. Zeng JH, Liu YX, Yuan J, Wang FX, Wu WB, Li JX, et al. First Case of COVID-19 Infection with Fulminant Myocarditis Complication: Case Report and Insights. Infection. 2020;48(5):773-777. https://doi.org/10.1007/s15010-020-01424-5

89. Yu CM, Wong RSM, Wu EB, Kong SL, Wong J, Yip GWK, et al. Cardiovascular complications of severe acute respiratory syndrome. Postgrad Med J. 2006;82(964):140-144. https://doi.org/10.1136/pgmj.2005.037515

90. Xu X, Han M, Li T, Sun W, Wang D, Fu B, et al. Effective Treatment of Severe COVID-19 Patients with Tocilizumab. Proc Natl Acad Sci U S A. 2020;117(20):10970-10975. https://doi.org/10.1073/pnas.2005615117

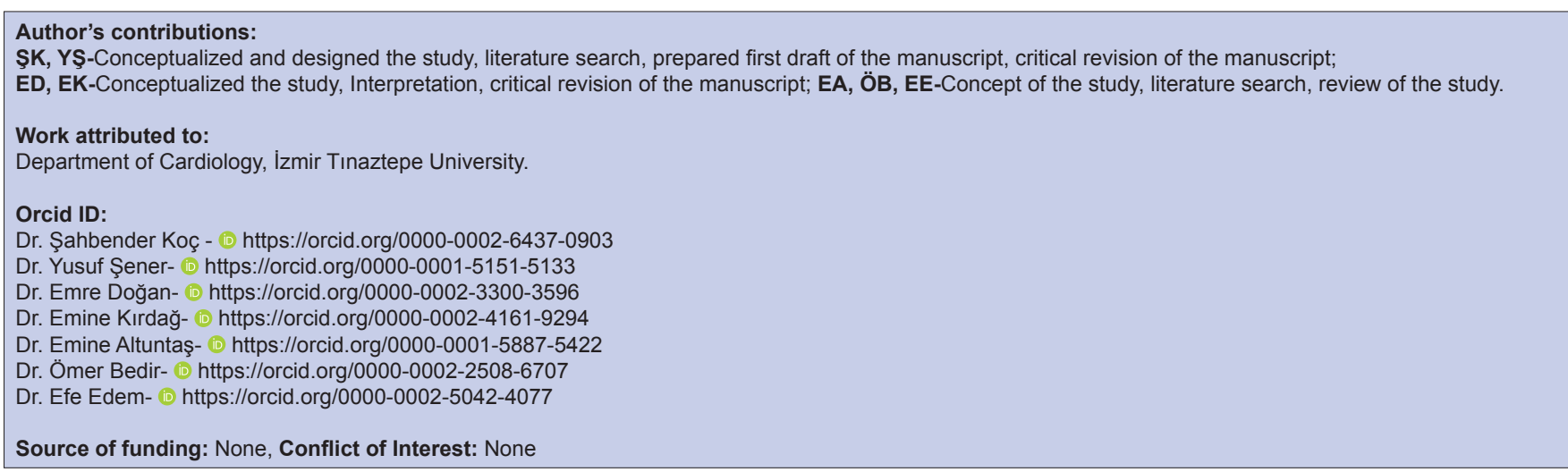

